\title{
Use veno-venous extra corporeal membrane oxygenation in elderly patients with post-cardiotomy hypoxia: the changing paradigm of respiratory support in adult respiratory distress syndrome
}

\author{
Sara Volpi", Federico Sertic, Kamen Valchanov and Ravi De Silva
}

\begin{abstract}
Background: Veno-venous extracorporeal membrane oxygenation (W-ECMO) support for ARDS treatment after cardiac surgery has progressed remarkably in the last 20 years. However, one of the limitations of a successful recover is age, being a powerful predictor of mortality.

Case presentation: In this case report we discuss a 78-year-old man who underwent aortic valve and aortic root replacement. The postoperative period was complicated by ARDS following aspiration pneumonia treated with WECMO weaned after 6 days. At two-year follow up, the patient made an excellent recover, being the second oldest person to survive $\mathrm{W}$-ECMO following cardiac surgery in the world.

Conclusion: In the literature there is no consensus regarding a specific age limit and results, in the use of ECMO in the elderly are scarce and inconsistent. We do not think advanced age is a contraindication to the use of ECMO.

Keywords: Veno-venous extracorporeal membrane oxygenation (W-ECMO), Acute respiratory distress syndrome (ARDS), cardiac surgery
\end{abstract}

\section{Background}

Acute respiratory distress syndrome (ARDS) is a lifethreatening complication that occasionally occurs after cardiac surgery. It can lead to rapidly progressive respiratory failure and has a high mortality rate [1]. Over the last 20 years, second generation veno-venous extracorporeal membrane oxygenation (VV-ECMO) support has emerged and progressed remarkably, becoming a valuable alternative therapy to provide good gas exchange and facilitate the recovery process in ARDS [2]. One of the limitations of a successful re- cover is age, being a powerful predictor of mortality [3]. We present the second oldest person to survive VV-ECMO following cardiac surgery in the world.

\section{Case presentation}

A 78-year-old man with a history of hypertension, atrial fibrillation and previous left lung tuberculosis presented with shortness of breath (NYHA II) and chest pain (CCS II-III). An echocardiogram showed calcified bicuspid aortic valve with mild regurgitation and a dilated ascending aorta with preserved biventricular function.

* Correspondence: doc.saravolpi@gmail.com

Department of Cardiothoracic Surgery, Royal Papworth Hospital, Cambridge CB23 3RE, UK 


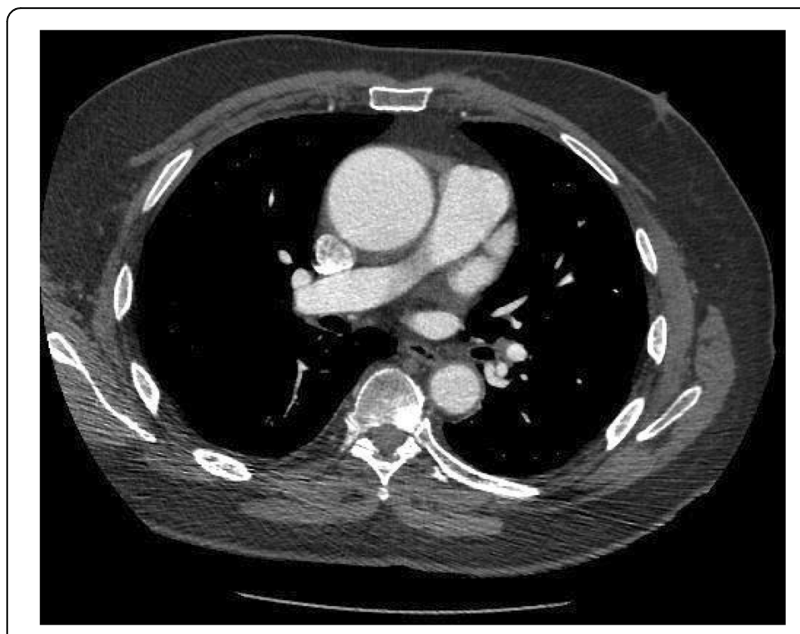

Fig. 1 CT Aorta showing aortic dilatation. No signs of dissection

Cardiac CT scan confirmed maximal ascending aorta dilatation of $5.2 \mathrm{~cm}$ (Fig. 1). The coronary angiogram showed no coronary artery disease. The Logistic EuroSCORE was $14.74 \%$. Therefore, he underwent aortic valve and aortic root replacement with left atrial appendage excision using a $25 \mathrm{~mm}$ Hancock II bioprosthesis and a $28 \mathrm{~mm}$ Hemashield graft. The patient was weaned from cardiopulmonary bypass ventricularly paced with Noradrenaline. The bypass time was $116 \mathrm{~min}$ with a cross clam time of $100 \mathrm{~min}$ using a retrograde cardioplegia technique. Protamine was used to reverse the heparin effect. The intraoperative transoesophageal echocardiogram was satisfactory and the patient was transferred to the Intensive Care Unit (ICU) in stable condition. The day after surgery he was brought back to

Table 1 Ventilation setting and arterial blood gas showing metabolic acidosis

\begin{tabular}{ll}
\hline Variable & Value \\
\hline Ventilation Mode & Pressure Regulated Volume Control (PRVC) \\
Respiratory Rate & $14 \mathrm{bpm}$ \\
PEEP & $12 \mathrm{~cm} \mathrm{H} \mathrm{C}_{2}$ \\
$\mathrm{PIP}$ & $30 \mathrm{~cm} \mathrm{H} \mathrm{O}$ \\
Tidal Volume & $683 \mathrm{~mL}$ \\
$\mathrm{FiO} 2$ & $100 \%$ \\
$\mathrm{PaO} 2$ & $6.41 \mathrm{kPa} \downarrow$ \\
$\mathrm{SaO} 2$ & $85.1 \% \downarrow$ \\
$\mathrm{PaCO} 2$ & $6.23 \mathrm{kPa}$ \\
$\mathrm{pH}$ & $7.34 \downarrow$ \\
$\mathrm{HCO} 3$ & $24.5 \mathrm{Mmol} / \mathrm{l}$ \\
Lactate & $2.6 \mathrm{mEq} / \mathrm{l} \uparrow$ \\
\hline
\end{tabular}

theatre for bleeding. Despite several bronchoscopies with removal of large amounts of clots, the patient remained hypoxic (Table 1). ARDS following aspiration pneumonia with pulmonary hemorrhage was diagnosed based on the Berlin definition. Therefore, he was supported with VV-ECMO, according to NICE and Extracorporeal Life Support Organization (ELSO) Guidelines [4], on day 4 after surgery together with continuous veno-venous hemofiltration $(\mathrm{CVVH})$ for refractory metabolic acidosis. Single VV-ECMO cannulation with bi-caval dual-lumen cannula (Avalon ELITE ${ }^{\mathrm{rm}}$, Avalon Laboratories, USA) was performed percutaneously through the right internal jugular vein and a 4-1 flow was established (Fig. 2a). In the following days, he became hemodynamically more stable and the gas exchange and CXR improved consistently (Fig. 2b). VV-ECMO and CVVH were weaned off in 6 days. A CT head, thorax, abdomen and pelvis done as per ECMO protocol ruled out intracranial pathologies, features of colitis and gut ischaemia and chest pathologies. The total patient stay in ICU was 22 days. He made a good recovery and he was discharged to a secondary facility for further rehabilitation. At two-year follow up, the patient made excellent progress, being one if the oldest person to survive VV-ECMO following cardiac surgery in the world. His ECG shows sinus rhythm and the chest X-ray is unremarkable (Fig. 2c).

\section{Discussion and conclusion}

Current indications and contraindications for appropriate use of Extracorporeal-Membrane-Oxygenation (ECMO) are set by the Extracorporeal-Life-Support-Organization (ELSO) [4]. In the ELSO guidelines advanced age is reported as a relative contraindication even though a specific threshold is not described [3]. The largest available trial (CESAR trial) on the use of VV-ECMO for the treatment of ARDS did not include any patients over the age of 65 years or any post-operative patients [5]. The postcariotomy veno-venous ECMO area is not well explored in the literature. In particular, the only available literature that reports the use of VV-ECMO following cardiac surgery for the treatment of ARDS is based on 2 case series [1, 2]. They both concluded that the VV-ECMO is a feasible option in the treatment of ARDS following cardiac surgery when conventional conservative management fails. Nakamura et al. presented a series of 11 patients with a survival to hospital discharge of $63.6 \%$ and the non-survivors were significantly older $(p<0.01)$ [1]. Song et al. presented a series of 13 patients with a survival to hospital discharge of $53.8 \%$ with the oldest survival being 74-years-old [2].

These patients differ form veno-venous ECMO for respiratory failure due to other causes in few ways. 


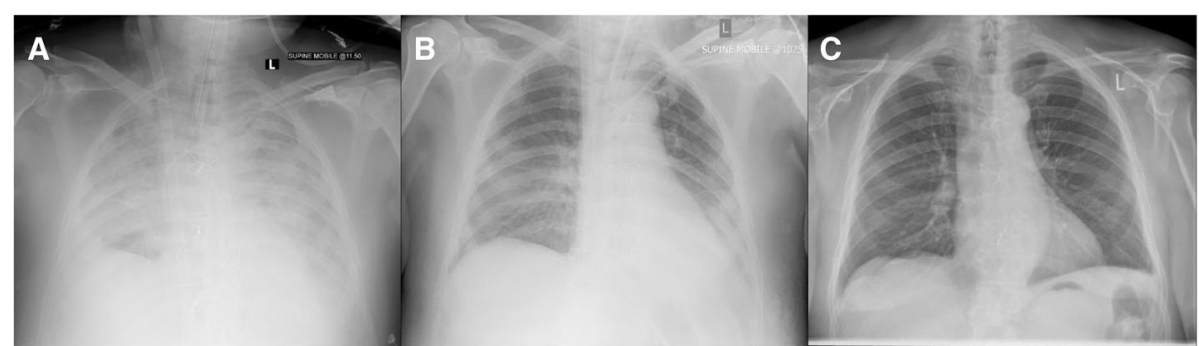

Fig. 2 Chest X-Rays performed: (a) after W-ECMO insertion: patchy airspace of opacification bilaterally. Features in keeping with ARDS; (b) 6 days after W-ECMO insertion, immediately before weaning: significant improvement in the bilateral perihilar pulmonary infiltrates; (c) at three-months follow up: heart size normal, lungs and pleural spaces clear

First of all, the cause of respiratory failure is known (such as aspiration pneumonia in our case). Moreover, the patients are already in a centre for advanced respiratory failure management, and institution of ECMO can be done early. Furthermore, the cardiac function is normal, unlike elderly patients from the community who may have cardiac disease. Finally, co-morbidities like malignancy have already been ruled out.

We present the case of a 78-years-old man who underwent AVR + ARR and developed severe ARDS post-operatively requiring VV-ECMO. He survived to hospital discharge and at 2-years follow-up he is doing remarkably well, being the second oldest survivor, to the best of our knowledge, to VV-ECMO after cardiac surgery in the world.

In conclusion, advanced age has been described as a relative contraindication to the use of ECMO. However, in the literature there is no consensus regarding a specific age limit and results in the use of ECMO in the elderly are scarce and inconsistent. We described a case of elderly patient who benefitted from extracorporeal support. Although mortality is higher in the elderly, for carefully selected postcardiotomy patients, ECMO support can be valuable and lead to excellent recovery.

\section{Abbreviations}

W-ECMO: Veno-venous extracorporeal membrane oxygenation; ARDS: Acute respiratory distress syndrome; ICU: Intensive Care Unit; CWH: continuous veno-venous hemofiltration; ELSO: Extracorporeal-Life-Support-Organization; AVR: aortic valve replacement; ARR: aortic root replacement

\section{Acknowledgements}

All collaborators who contributed to this manuscript were included as authors of the paper. There is no source of funding to be declared for any of the authors.

\section{Funding}

There was no funding for the writing of this case-report.

\section{Authors' contributions}

SV and FS drafted the manuscript. RDS and KV revised the manuscript for intellectual content and participated until the final approval of the submitted version. RDS was also the operating surgeon and KV the anesthetist in theatre and in intensive care looking after the patient. All authors read and approved the final manuscript.

Ethics approval and consent to participate

Not needed.

\section{Consent for publication}

Written informed consent was obtained from the patient for publication of this case report and any accompanying images.

\section{Competing interests}

The authors declare that they have no competing interests.

\section{Publisher's Note}

Springer Nature remains neutral with regard to jurisdictional claims in published maps and institutional affiliations.

Received: 2 July 2018 Accepted: 8 January 2019

Published online: 14 January 2019

\section{References}

1. Nakamura H, Yamaguchi H, Amano A, Nakao T. Venovenous extracorporeal membrane oxygenation is effective against post-cardiotomy acute respiratory failure in adults. Gen Thorac Cardiovasc Surg. 2013;61(7):402-8.

2. Song JH, Woo WK, Song SH, Kim HH, Kim BJ, Kim HE, et al. Outcome of veno-venous extracorporeal membrane oxygenation use in acute respiratory distress syndrome after cardiac surgery with cardiopulmonary bypass. J Thorac Dis. 2016 Jul;8(7):1804-13.

3. Mendiratta P, Tang X, Collins RT, Rycus P, Brogan TV, Prodhan P. Extracorporeal membrane oxygenation for respiratory failure in the elderly: a review of the Extracorporeal Life Support Organization registry. ASAIO J Am Soc Artif Intern Organs 1992. 2014;60(4):385-90.

4. Bastin AJ, Firmin R. Extracorporeal membrane oxygenation for severe acute respiratory failure in adults: NICE guidance. Heart Br Card Soc. 2011 Oct; 97(20):1701-3.

5. Peek GJ, Clemens F, Elbourne D, Firmin R, Hardy P, Hibbert C, et al. CESAR: conventional ventilatory support vs extracorporeal membrane oxygenation for severe adult respiratory failure. BMC Health Serv Res. 2006 Dec 23;6:163. 